\title{
Student Engagement Online - Does gender make a difference? A Pilot Study in One Engineering and Technology Course
}

\author{
Angela D Hutson-Stone, Indiana University Purdue University, Indianapolis \\ Dr. Julie M Little-Wiles, Indiana University-Purdue University, Indianapolis
}

Dr. J. M. Little-Wiles is currently a Visiting Lecturer in the Department of Technology Leadership and Communication in the School of Engineering and Technology at Indiana University-Purdue University Indianapolis (IUPUI) where she teaches courses in Leadership Philosophy, Leadership Theory, Ethics, Technical Writing and International Management. Prior to her appointment at IUPUI after receiving her $\mathrm{PhD}$ from Purdue University in 2012, she worked in manufacturing for almost 17 years including 15 years spent with Chrysler Corporation in Manufacturing Engineering. Her research interests include leadership in multiple environments including in the STEM fields and higher education with particular interest to females and minorities; and online teaching and learning. She is active in ASEE as she is a current officer for the Women's Division (WIED) and also participates with reviewing papers for several other divisions annually. (e-mail: jlittlew@iupui.edu).

\section{Dr. Eugenia Fernandez, Indiana University Purdue University, Indianapolis}

Eugenia Fernandez is an Associate Professor of Computer and Information Technology and Chair of the Department of Computer Information and Graphics Technology in the Purdue School of Engineering and Technology at Indiana University-Purdue University, Indianapolis. She is a Fellow of the Mack Center at Indiana University for Inquiry on Teaching and Learning and an Editor of the Journal of Scholarship of Teaching and Learning. Her research focuses on the scholarship of teaching and learning related to learning with technology.

\section{Prof. Patricia Fox, Indiana University Purdue University, Indianapolis}

Patricia Fox is the Associate Chair of the Technology Leadership and Communication Department at the Purdue School of Engineering and Technology at IUPUI. Pat teaches leadership, ethics, and sustainability courses. She has been very active in ASEE for a number of years, which included three terms on the ASEE Board of Directors. Pat is an ASEE Fellow. 


\title{
Student Engagement Online - Does gender make a difference? A Pilot Study in One Engineering and Technology Course
}

\begin{abstract}
As the online learning explosion continues in response to advancements in technology, students are now being offered alternative means of educational delivery formats including hybrid and/or entirely online classes within major engineering and technology schools. Does gender play a significant role in how students engage with online courses? This research explored student engagement by gender in a pilot study of one sophomore level ethical decision making course in the School of Engineering and Technology at Indiana University-Purdue University Indianapolis (IUPUI). The results demonstrated very few significant differences in regard to online engagement and gender. Based on conflicting results and our small female sample size $(n=12)$, we conclude there was not enough data collected. Further research is indicated.
\end{abstract}

\section{Introduction}

Online learning is growing by leaps and bounds, and engineering and technology schools are not exempt from this digital explosion. Traditional learning means students are in a classroom with a teacher physically onsite. In response to advanced technology, students are now being offered alternative means of educational delivery formats including hybrid or entirely online classes (classes delivered via the internet). This is also referred to as distance education. Tools such as chat rooms, email messages, and discussion forums enhance the online learning process. For educators, it becomes critical to the design, delivery, and even the decision of what courses to offer online to understand the differences in student engagement using these tools. One item that may play a role in online engagement is gender. Gender is frequently mentioned, but currently research and data are limited for this area. ${ }^{1}$

A student's gender may impact how they engage in an online course. This engagement can affect a student's overall education. This study will investigate if females or males use the same or different patterns, and what types of interaction with the online system each utilizes, specifically within an engineering and technology course. Additionally, we will explore how the rate of logging into the learning management system differs. Are the same or different tools used within the course Learning Management System (LMS) and do any of these factors mentioned above impact their final grades for the course?

In order to deliver quality education and offer students the opportunity be successful in online courses, educational institutions need to understand their students and their learning as well as engagement styles. This research will identify if gender needs to be addressed in the delivery of online education to help students be more successful.

\section{Literature Review}


Research in the area of online learning continues to expand daily, and a multitude of research surrounds online learning given the current technology available. According to CampusTechnology.com, the number of college students taking at least one online course has come close to doubling ${ }^{2}$. In fact during a five year time span, the number went from 23 percent to 45 percent $^{2}$. But very little research currently exists surrounding gender engagement in online courses to reference or compare. The most in-depth research found on gender was more than 10 years old ${ }^{3}$. This research references online learning in an internet and web design course. In it, McSporran and Young state that the number of women in technology classes is lower than other classes. Survey results also found that women preferred online courses to traditional classroom settings. In that particular course, it was found that the women scored higher than the men on assignments, projects, and the final exam. In addition, women engaged with the online sessions and quizzes more often than the men $^{3}$. Beer, Clark and Jones noted no significant differences in gender in online learning in their study and suggested that the closing of the technology and access gap between the sexes could be the reason for the lack of difference ${ }^{4}$. The lack of available research could be considered valuable as well.

Three additional categories of research were found with some indirect relation to the topic of gender engagement in online learning. These categories of research were: 1) gender engagement and learning styles, 2) gender in the traditional classroom setting, and 3) general student engagement in online learning. In the first category (gender engagement and learning styles in relation to building online courses), gender was found to be a factor in the learning style and how that affected engagement. The overall direction was found that those developing an online course should consider learning styles and gender to be significant factors ${ }^{1}$. In the remaining two categories, the research has been directed mostly toward the development of the online learning itself $^{5}$. Technology growth and the desire to deliver learning in a variety of methods has sparked research on what is the best way to provide the education students' desire; as well as what is the best interaction needed (or expected) from instructors and students for success particularly online. However, it is mentioned in multiple articles ${ }^{1,3}$ that specific research in the area of gender engagement is significantly lacking. Furthermore, there is only a limited understanding of the interaction between the student, the technology, and the coursework ${ }^{1}$.

In researching gender engagement online, gender articles related to the general topic of online learning were more prevalent than the specific topic of engagement. In addition, the research is more qualitative than quantitative in nature. Psychological analysis of gender tendencies revealed that more women seek online courses to level the gender gap presented in the physical classroom $^{6}$. Furthermore, Kramarae indicates that regardless of venue (online or traditional setting) men and women react based on a specific set of gender related characteristics ${ }^{7}$. In the same way, online class designers target the female gender to help meet life balance constraints. Underscoring that point, McSporran and Young state online classes target women and older 
students who are more motivated and better at communicating online as opposed to male students who require more discipline that physical classrooms provide ${ }^{3}$.

It is hypothesized that most engineering and technology classes are delivered via the traditional method. But it is a fact that fewer women enroll in these courses ${ }^{3}$. Online courses are being targeted to bridge the gap between genders within this environment. Studies show women's discomfort in either the traditional classroom or online courses where gender is identified. Online courses could allow this distinction to be obscured, potentially allowing a more genderneutral environment to occur, thus balancing gender engagement.

\section{Method}

The population for this pilot study was students enrolled in one sophomore level ethical decision making course in the School of Engineering and Technology at Indiana University-Purdue University Indianapolis (IUPUI). The pilot featured two online sections of the course taught by two different instructors with various instructional strategies employed. Both of the sections were held entirely online within the learning management system (LMS) and shared the same course textbook, major assignments and bi-weekly synchronous chats held within the LMS environment.

A census of the sampling frame of all male and female students enrolled in these two sections of the ethical decision making course was used. The data was collected from the Learning Management System (Oncourse). Further, the data was collected entirely from the site stats tool in the LMS for the two online sections to better understand if any of these elements contributed both to the student grade and then the resulting engagement in the course. The data collected (including that from the site stats tool) provided per student:

- Gender

- Total site activity and usage (this is a wide variety of activity within the course site including login, chat, message, access assignments tabs, access syllabus, and more)

- Total Site Visits (to the course site): = total logins to the course site no matter how they get there; through Oncourse, Onestart, etc.

- Chat room activity (required bi-weekly synchronous chats)

- Message activity (messages are similar to email within the LMS system and can be forwarded to outside email as an option)

- Course Letter grade earned (A, B, C, D, F)

- Course Grade percentage earned

The main PI collected and then coded the data for the research team to work with under IRB approval. Only the main PI had access to the original data with student identifiers. The information gathered is not identifiable and does not reflect which section the student was enrolled into or completed. A random number was assigned to each student as an identifier. The data was stored in Microsoft Excel 2010 and SPSS 21 for Windows to determine the number of 
men and women in the course, to compare the grades of men and women in the course, and to determine if a relationship or correlation exists between gender, final grades and online (via sources listed above) activity among the students.

\section{Results}

\section{Demographics}

For the two pilot sections, $76 \%$ of participants were male while just $24 \%$ of the participants were female.

Students' final grades were collected along with total site usage, total chat activity, and total message activity, and total site visits within the LMS. Averages of these variables by gender appear in Table 1.

Table 1. Mean by Gender for Study Variables

\begin{tabular}{|l|c|c|c|c|c|c|}
\hline Gender & $\begin{array}{c}\text { Mean } \\
\text { Total Site } \\
\text { Activity }\end{array}$ & $\begin{array}{c}\text { Mean } \\
\text { Total Site } \\
\text { Visits }\end{array}$ & $\begin{array}{c}\text { Mean } \\
\text { Chat } \\
\text { Activity }\end{array}$ & $\begin{array}{c}\text { Mean } \\
\text { Message } \\
\text { Activity }\end{array}$ & $\begin{array}{c}\text { Mean } \\
\text { Course } \\
\text { Grade } \\
\text { \% }\end{array}$ & $\begin{array}{c}\text { Corresponding } \\
\text { Letter Grade }\end{array}$ \\
\hline $\mathbf{1 2}$ females & 552.6 & 143.9 & 134.3 & 64.8 & $86.3 \%$ & $\mathrm{~B}$ \\
\hline $\mathbf{3 7}$ males & 400.3 & 109.8 & 133.3 & 55.6 & $89.4 \%$ & $\mathrm{~B}+$ \\
\hline
\end{tabular}

Analysis

The following statistical analysis took place to determine significance of gender and LMS usage:

1. Is there any relationship between gender and the students' final grade?

2. Is there any relationship between gender and total visits with the students' final grades?

3. Is there any relationship between gender and LMS functions (total site visits, total site activity, chat activity, message activity)?

4. Is there a difference between the pattern of how each gender utilized the LMS functions?

\section{Relationship between gender and the students final grade}

An independent-samples $t$ test was calculated comparing the mean course grade of male students to the mean course grade of female students. No significant difference was found $(t(47)=.549, p$ $>$.05). The mean course grade of male students $(m=89.4, s d=13.5)$ was not significantly different from the mean grade of female students $(m=86.3, s d=21.5)$.

\section{Relationship between gender, total site visits, and final grade}

To determine if gender and total site visits impact final course grade, a two factor ANOVA was conducted. To do so, total site visits were coded into four categories: High, Above Average, Below Average, and Low. The total site visit quartiles were used to place each student into one of these categories (see Table 2). 
Table 2. Total Site Visit by Quartiles

\begin{tabular}{|l|c|c|}
\hline $\begin{array}{c}\text { Total Site } \\
\text { Visit Category }\end{array}$ & Frequency & Percent \\
\hline Low & 13 & 26.5 \\
\hline Below Average & 13 & 26.5 \\
\hline Above Average & 11 & 22.4 \\
\hline High & 12 & 24.5 \\
\hline
\end{tabular}

A 2 (gender) x 4 (total site visit category) between-subjects factorial ANOVA was calculated comparing the final course grades for students who were male or female and the frequency of their visits to the LMS. The main effect for gender was significant $(F(1.41)=4.48, p<.05)$. Male students earned higher final grades $(m=89.4, s d=13.5)$ than female students $(m=86.3, s d$ $=21.5)$. The main effect for total site visits frequency was also significant $(F(3.41)=14.291, p$ $<.001)$. Tukey's HSD post hoc tests were used to determine the nature of the differences. Students with low visit frequency had significantly lower grades $(m=75.1, \mathrm{sd}=24.07)$ than did those with below average $(m=91.3, s d=7.39)$, above average $(m=95.6, s d=4.00)$ or high $(m$ $=94.1, s d=4.93)$ visit frequency. Finally, the interaction was significant $(F(3.41)=5.60, p<$ $.05)$. As shown in Figure 1, female students with low visit frequency earned significantly lower grades $(m=41.2, s d=8.31)$ than male students with low visit frequency $(m=81.3, s d=3.55)$.

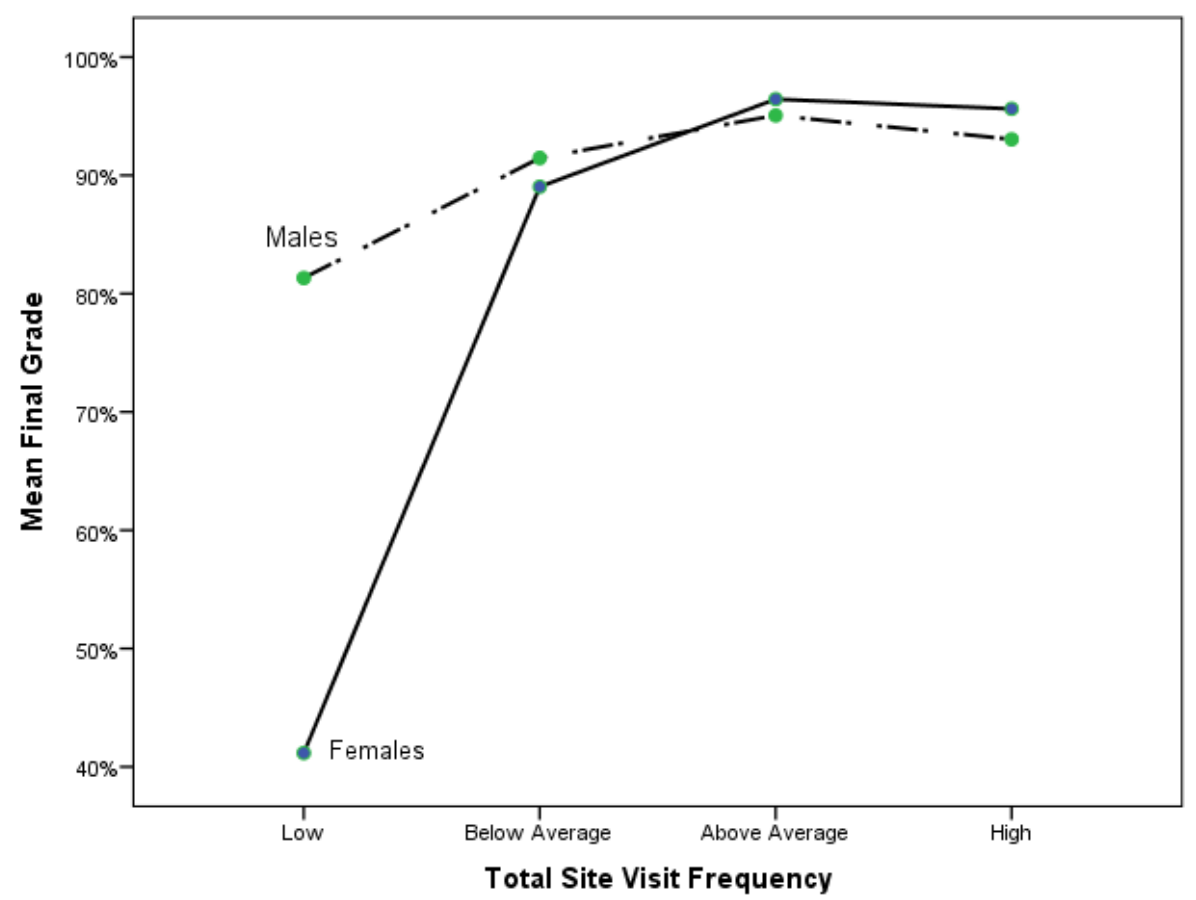

Figure 1. Interaction of Gender and Total Site Visit on Final Grades 
As the main effect results for gender and final grade contradict the previous $t$ test results, a closer examination of the data (see Figure 3 ) revealed 3 clear outliers for final grades ( 2 females and 1 male). When these 3 students were removed from the factorial ANOVA analysis, no significant results were found. This indicates that the small female sample size does not provide enough data for a conclusion regarding significance of gender in this analysis.

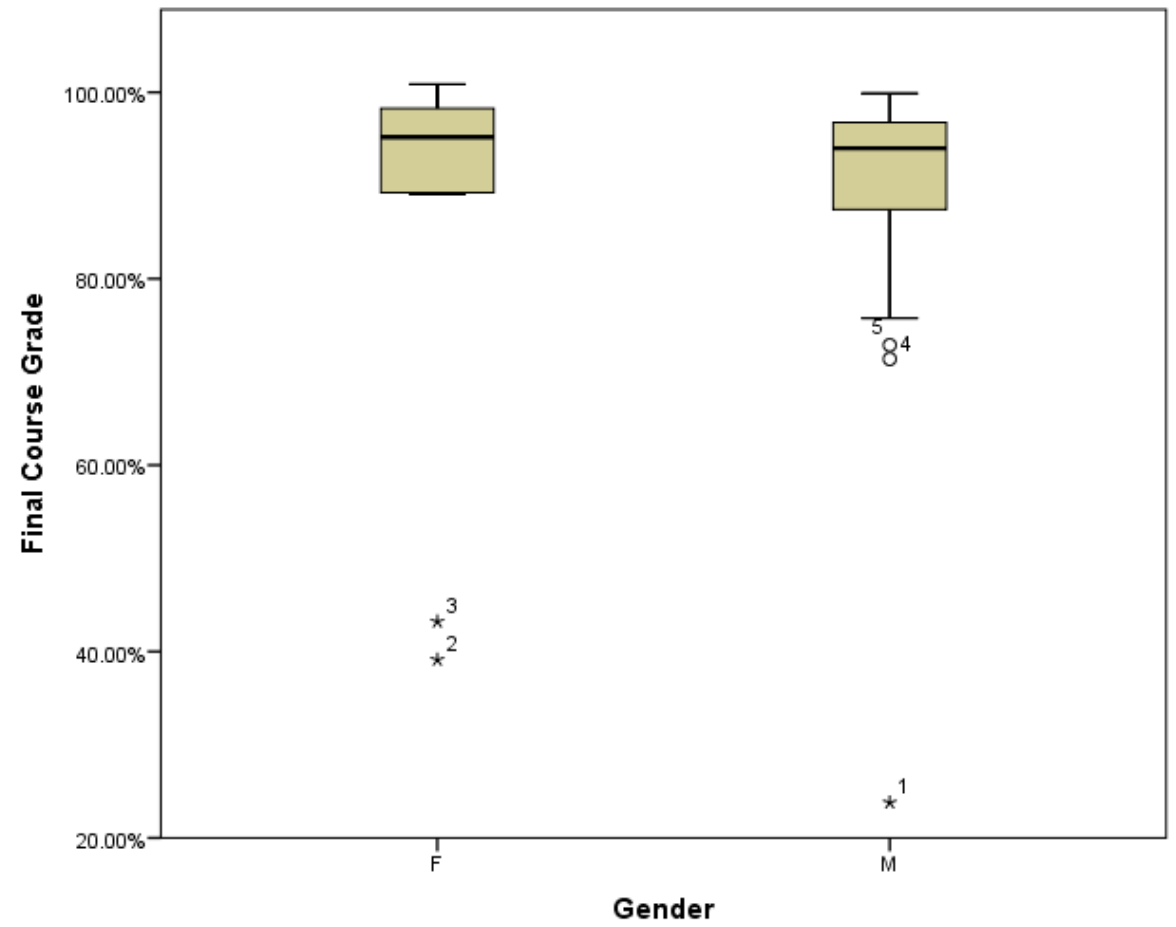

Figure 2. Final Course Grade Box Plot by Gender Shows 3 Outliers

\section{Relationship between gender and LMS functions}

Independent samples $t$ tests were calculated comparing the male and female means for each of the LMS functions: total site activity, total site visits, chat room activity, and message activity. The results of the tests are provided in Table 3. No significant differences were found.

Table 3. Independent $t$ test results for LMS Function by Gender

\begin{tabular}{|l|c|r|r|c|c|c|}
\hline & Gender & Mean & Std. Dev. & \multicolumn{1}{c|}{$\boldsymbol{t}$} & \multicolumn{1}{c|}{ df } & \multicolumn{1}{c|}{ Sig. } \\
\hline \multirow{2}{*}{ Total Site Activity } & $\mathrm{M}$ & 552.6 & 162.9 & 1.240 & 12.12 & .238 \\
\cline { 2 - 5 } & $\mathrm{F}$ & 400.3 & 415.2 & & & \\
\hline \multirow{2}{*}{ Total Site Visits } & $\mathrm{M}$ & 109.8 & 55.09 & 1.812 & 47 & .076 \\
\cline { 2 - 5 } & $\mathrm{F}$ & 143.9 & 61.64 & & & \\
\hline Chat Room & $\mathrm{M}$ & 133.32 & 78.302 & .040 & 47 & .968 \\
\hline
\end{tabular}




\begin{tabular}{|l|c|r|r|r|r|r|}
\hline Activity & F & 134.33 & 66.960 & & & \\
\hline \multirow{2}{*}{ Message Activity } & $\mathrm{M}$ & 55.65 & 31.49 & .941 & 47 & .352 \\
\cline { 2 - 7 } & $\mathrm{F}$ & 64.75 & 19.42 & & & \\
\hline
\end{tabular}

The high standard deviation in total site activity led to further analysis identifying 3 clear outliers ( 2 female and 1 male). Figure 3 shows a visual representation of the outliers.

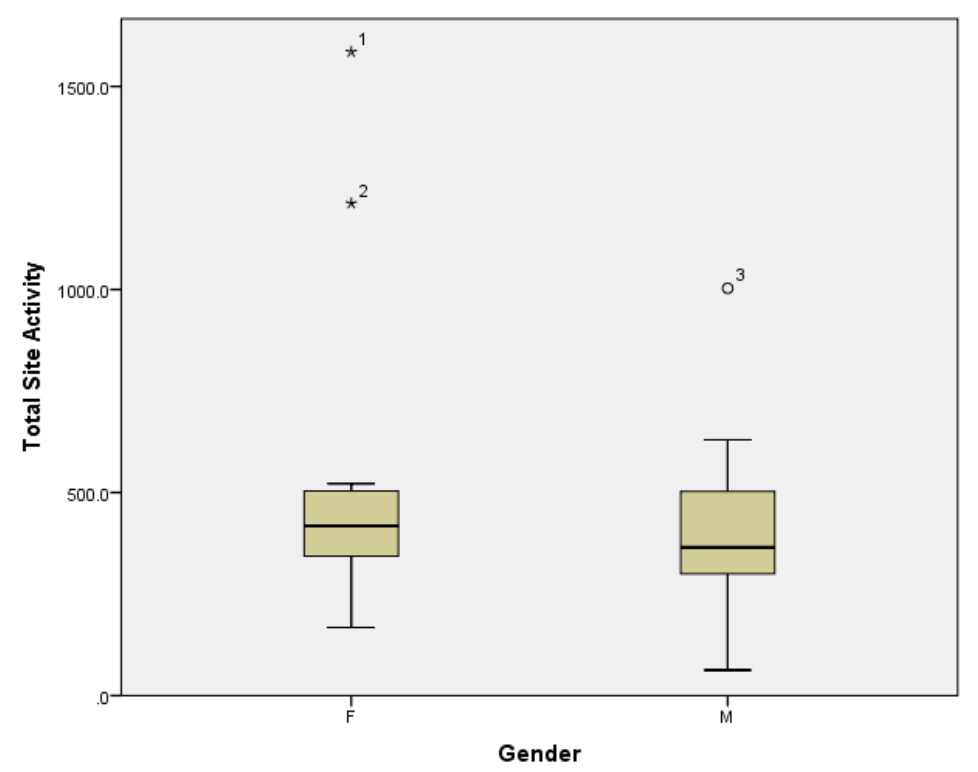

Figure 3. Total Site Activity Box Plots by Gender Shows 3 Outliers

Referring back to the SPSS data analysis, it is seen that the $t$ test for total site activity did not meet the Levene's Test for Equality of Variances $(F(47)=8.130, p<.05)$ However, when these three outliers were removed, Levene's test was satisfied $(F(44)=.649, \mathrm{p}>.05)$. The outliers were removed and the independent $t$ test was re-calculated comparing male and female means for total site activity. No significant difference was found $(t(44)=-.003, p>.05)$. The mean total site activity of male students ( $m=383.6, s d=128.9$ ) was not significantly different from the mean total site activity of female students $(m=383.4, s d=110.2)$.

NOTE: These three outliers were removed for any subsequent analysis involving total site activity.

\section{Relationship between gender to pattern of usage across all LMS functions}

A chi-square test of independence was calculated comparing gender to the pattern of mean usage totals across all LMS functions (as shown in Table 4). No significant relationship was found $\left(X^{2}(3)=3.91, p>.05\right)$. Gender and pattern of usage of LMS functions appear to be independent. 
Table 4. Mean Activity Totals by Gender

\begin{tabular}{|c|c|c|c|c|}
\hline & $\begin{array}{c}\text { Total } \\
\text { Site } \\
\text { Activity }\end{array}$ & $\begin{array}{c}\text { Total } \\
\text { Site } \\
\text { Visits }\end{array}$ & $\begin{array}{c}\text { Chat } \\
\text { Room } \\
\text { Activity }\end{array}$ & $\begin{array}{c}\text { Message } \\
\text { Activity }\end{array}$ \\
\hline F & 383.40 & 143.92 & 134.33 & 64.75 \\
\hline M & 383.60 & 109.78 & 133.32 & 55.65 \\
\hline
\end{tabular}

\section{Conclusion}

The results of this pilot study in one engineering and technology ethical decision making course demonstrated very few significant differences in regard to online engagement and gender, or on either's impact on final course grades. Analysis was conducted to determine if there was a relationship between gender and the students' final grade (independent samples $t$ test); if there was any relationship between gender and total site visits with the students' final grade (factorial ANOVA); if there was a dependence between gender and LMS functions (independent samples $t$ test); and if there was a difference between how each gender utilized the LMS functions (chisquare test of independence). The only significant credible result was related to total site visit frequency and course grade. Not surprisingly, students who visited the LMS site less frequently earned lower grades than other students who visited more often.

The lack of gender differences in course grades and LMS usage is consistent with Beer, Clark and Jones ${ }^{4}$ work, but contradicts McSporran and Young's ${ }^{3}$ results which indicated women earned higher grades in an online course. Based on our conflicting results, and our small female sample size $(\mathrm{n}=12)$, we conclude there was not enough data collected to appropriately draw meaningful conclusions for this engineering and technology course. Collecting larger samples may provide different results than the analysis of this pilot study found. Planned next steps to this research include the continuation of this study for the IRB approved two-year period with the expansion to all online sections available each and every semester including summer sessions. This should provide researchers up to six or seven sections to investigate each semester and at least three sections in the summer months providing that larger amount of data to be able to examine. Researchers are anxious to discover if those results will suggest new implications in the end or be similar to these found in the pilot study. Either way, given the lack of literature and research surrounding this topic, additional research must be done to validate the results and investigate a topic with a serious gap of knowledge. 


\section{References}

1. Garland, D. \& Martin, B. (2005). Do gender and learning style play a role in how online courses should be designed? Journal of Interactive Online Learning, 4(2), 67-81. Retrieved from http://www.ncolr.org/ jiol/issues/pdf/4.2.1.pdf

2. Bolkan, J. (June 24, 2013). Report: Students taking online courses jumps 96 percent over 5 years. Retrieved from http://campustechnology.com/articles/2013/06/24/report-students-taking-online-courses-jumps-96percent-over-5-years.aspx.

3. McSporran, M., \& Young, S. (2001). Does gender matter in online learning? Research in Learning Technology, 9(2), 3-15. Retrieved from http://www.researchinlearningtechnology.net/index.php/rlt/article/view/12024 doi:10.1080/0968776010090202

4. Beer, C., \& Clark, K., \& Jones, D. (2010). Indicators of engagement. In C.H. Stee, M.J. Keppell, P. Geric \& Housego (Eds.), Curriculum, technology \& transformation for an unknown future. Proceedings ascilite Sydney 2010, 75-86. Retrieved from http://www.ascilite.org.au/conferences/sydney10/procs/Beer-full.pdf

5. Monteith, K. (2002). Gendered learning and learning about gender online: A content analysis of online discussion. An ODELUCE, University of Stirling Report. Retrieved from http://www.odeluce.stir.ac.uk/docs/ Gendered\%20Learning.pdf

6. Goldberg, R. (2012, November 28). Women now outnumber men in college: How online education might help the gender gap. Retrieved from http://www.policymic.com/articles/19734/women-now-outnumber-menin-college-how-online-education-might-help-the-gender-gap

7 American Association of University Women Educational Foundation [AAUWEF]. (2001). The third shift: Women learning online. (Excerpts). Washington, DC: Kramarae, C. Retrieved from http://pages.uoregon.edu/cheris/PDF/ third\%20shift.pdf. 